\title{
Reclassification of Sphaerobacter thermophilus from the subclass Sphaerobacteridae in the phylum Actinobacteria to the class Thermomicrobia (emended description) in the phylum Chloroflexi (emended description)
}

\author{
Philip Hugenholtz ${ }^{1} \dagger$ and Erko Stackebrandt ${ }^{2}$ \\ ${ }^{1}$ Department of Environmental Science, Policy and Management, 151 Hilgard Hall, University \\ of California Berkeley, Berkeley, CA 94720-3110, USA \\ ${ }^{2} \mathrm{DSMZ}$ - Deutsche Sammlung von Mikroorganismen und Zellkulturen, Mascheroder Weg 1b, \\ D-38124 Braunschweig, Germany
}

Correspondence

Philip Hugenholtz

phugenholtz@lbl.gov
Sphaerobacter thermophilus is a Gram-positive, non-sporeforming bacterium that was isolated from an aerobic thermophilic sludge (Hensel et al., 1989). Comparative analysis of a partial $16 \mathrm{~S}$ rRNA sequence obtained by reverse transcriptase sequencing (GenBank/EMBL/DDB) accession no. X53210) suggested, at the time, that $S$. thermophilus was the most deeply branching member of the phylum Actinobacteria (high-G $+\mathrm{C}$, Gram-positive bacteria; Demharter et al., 1989). This phylum-level assignment has been disseminated through the literature (Carreto et al., 1996; Embley \& Stackebrandt, 1994; Monciardini et al., 2003; Rainey \& Stackebrandt, 1993; Rappé et al., 1999; Shooner \& Tyagi, 1995; Wiegel, 1998), culminating in a formal classification as a novel suborder of the Actinobacteria (Stackebrandt et al., 1997). However, the initial analysis by Demharter et al. (1989) was compromised by insufficient reference sequences (outgroups) and, as more $16 \mathrm{~S}$ rRNA gene sequences have become available, it is apparent that $S$. thermophilus is not reproducibly affiliated

Published online ahead of print on 20 August 2004 as DOI 10.1099/ ijs.0.03028-0.

tPresent address: DOE Joint Genome Institute, 2800 Mitchell Creek Bldg 400-404, Walnut Creek, CA 94598, USA.

The GenBank/EMBL/DDBJ accession number for the 16S rRNA gene sequence of Sphaerobacter thermophilus DSM $20745^{\top}$ is AJ420142. with the Actinobacteria and is instead a member of the phylum Chloroflexi (green non-sulfur bacteria; Björnsson et al., 2002; Hugenholtz et al., 1998).

We have obtained an almost complete 16S rRNA gene sequence for the type strain of $S$. thermophilus (DSM $20745^{\mathrm{T}}$ ) using methods described previously (Rainey et al., 1996) and confirm that its phylogenetic placement is within the Chloroflexi (Fig. 1), on the basis of evolutionary distance and Bayesian inference as previously described (Janssen \& Hugenholtz, 2003). Fig. 1 shows only the Chloroflexi phylum sequences (ingroup) used in the analysis; they were rigorously tested for monophyly using a variety of bacterial outgroup sequences representing multiple phyla (not shown; datasets available on request), as described previously (Dalevi et al., 2001).

The closest relative of $S$. thermophilus is Thermomicrobium roseum (Fig. 1), which it resembles phenotypically. Both are thermophilic, obligately aerobic, chemoheterotrophic, catalase-positive, non-motile, non-spore-forming, short irregular-shaped rods with similar DNA G + C content (Demharter et al., 1989; Garrity \& Holt, 2001b). The cell membrane of $T$. roseum contains distinctive long-chain diols instead of the familiar glycerol-based lipids (Pond et al., 1986) and these have been postulated to contribute to membrane stabilization at high temperatures (Pond \& 


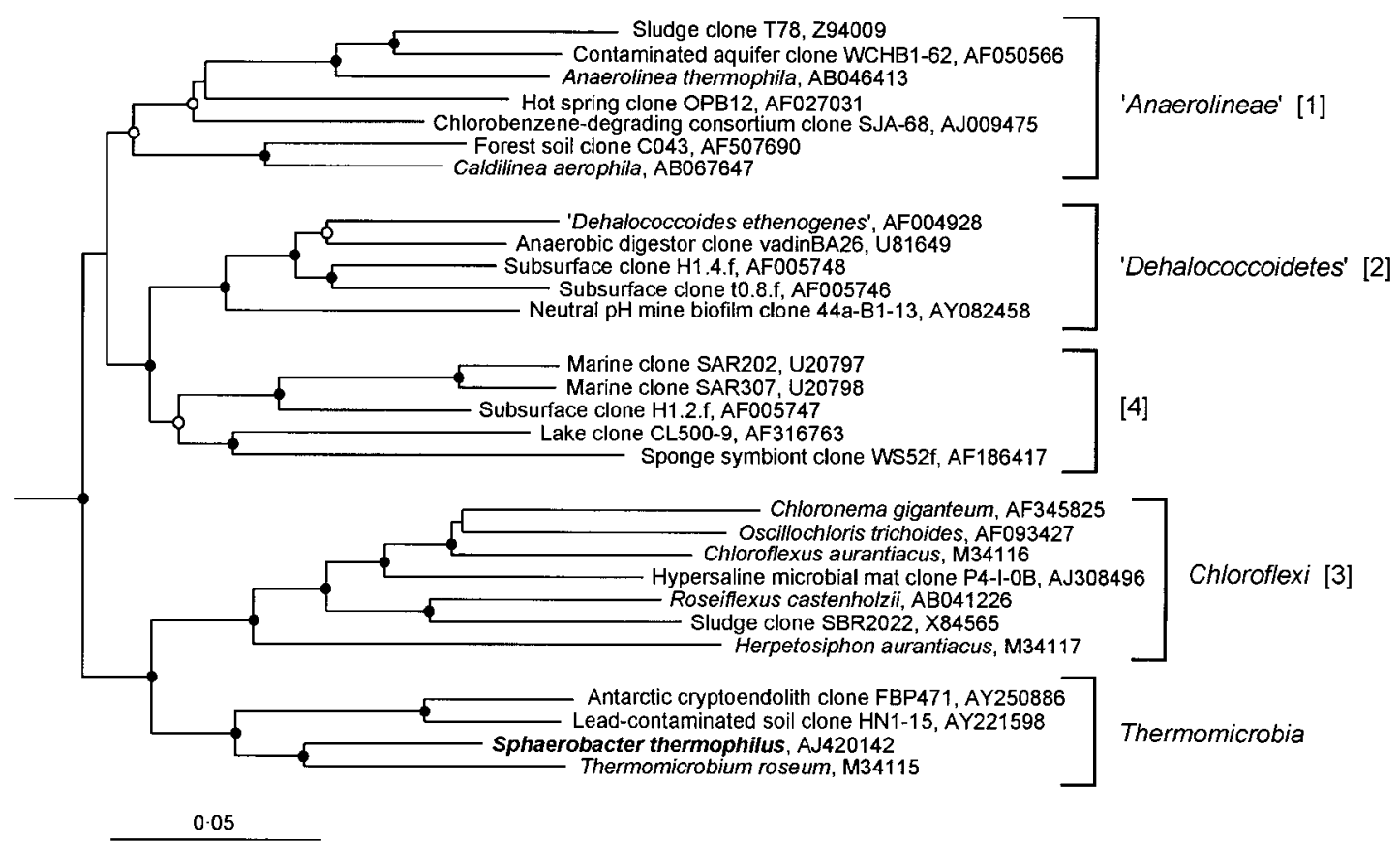

Fig. 1. Evolutionary distance tree of the phylum Chloroflexi based on comparative analysis of $16 \mathrm{~S}$ rRNA gene sequences showing the phylogenetic affiliation of $S$. thermophilus (shown in bold). Branch points supported by evolutionary distance bootstrap resampling and Bayesian posterior probabilities are indicated by filled circles (bootstrap proportion and posterior probability values $>90 \%$ ) and open circles (both values $>75 \%$ ). Escherichia coli (X80725), Bacillus subtilis (D26185) and Corynebacterium diphtheriae (X84248) were used as outgroups (not shown). Subdivision (class)-level groupings are indicated by brackets to the right of the figure. Class names follow Garrity \& Holt (2001a, b), and informally proposed classes (in quotation marks) are based on representative species names. The numbers in brackets following these names are according to the subdivision numbering in Hugenholtz et al. (1998). Bar, 0.05 changes per nucleotide.

Langworthy, 1987). S. thermophilus has not been investigated for its cell membrane composition, but given its relationship to $T$. roseum and the fact that it is a thermophile, it may also contain diol-based lipids.

T. roseum has long been recognized to be affiliated with the phylum Chloroflexi on the basis of $16 \mathrm{~S}$ rRNA comparative analysis (Woese, 1987), but is currently classified in its own bacterial phylum, Thermomicrobia (Garrity \& Holt, 2001b). We propose to transfer the class Thermomicrobia to the phylum Chloroflexi to acknowledge this phylogenetic relationship formally (Fig. 1). In addition to the class Thermomicrobia, at least four other major lineages exist in the phylum Chloroflexi (Fig. 1), three of which now have cultivated representatives: the well-characterized class Chloroflexi, containing the phototrophic genera Chloroflexus, Chloronema, Heliothrix and Oscillochloris and the chemoheterotrophic genus Herpetosiphon (Garrity \& Holt, 2001a); the 'Dehalococcoidetes', containing the tetrachloroethene-respiring coccus 'Dehalococcoides ethenogenes' (Maymó-Gatell et al., 1997); and, most recently, the 'Anaerolineae', containing the thermophilic filamentous bacteria Anaerolinea thermophila and Caldilinea aerophila (Sekiguchi et al., 2003). The 'Anaerolineae' are not monophyletic in all analyses (note node support $<90 \%$ in Fig. 1) and may need to be subdivided as new sequences come to hand. Detailed comparative studies of S. thermophilus and other members of the Chloroflexi may reveal unifying chemotaxonomic and ultrastructural features of this interesting phylum. For example, some members of the Chloroflexi, including S. thermophilus, have unusual cell envelopes rich in protein and lacking significant amounts of peptidoglycan (Demharter et al., 1989; Maymó-Gatell et al., 1997; Merkel et al., 1980).

We conclude, on the basis of $16 \mathrm{~S}$ rRNA gene sequence comparative analysis, that $S$. thermophilus should be reassigned to the class Thermomicrobia in the phylum Chloroflexi. We suggest retaining the order and family proposed for S. thermophilus (Sphaerobacterales and Sphaerobacteraceae, respectively; Stackebrandt et al., 1997) in the class Thermomicrobia until a more rigorous comparison of $S$. thermophilus and T. roseum is performed and further representatives of this class are characterized.

\section{Emended description of the phylum Chloroflexi Garrity and Holt 2001}

The phylum Chloroflexi is a deep-branching lineage of the Bacteria. On the basis of comparative 16S rRNA gene sequence analysis of isolates and environmental clones, the phylum can be divided into at least five major subdivisions, 
including the classes Chloroflexi and Thermomicrobia. Mostly Gram-negative, filamentous bacteria with unusual cell envelopes. No peptidoglycan or atypical peptidoglycan present in cell walls. Lipopolysaccharide-containing outer membrane not present in studied representatives.

\section{Emended description of the class Thermomicrobia Garrity and Holt 2001}

The class Thermomicrobia subdivides into two orders with validly published names: Thermomicrobiales Garrity and Holt 2001 and Sphaerobacterales Stackebrandt, Rainey and Ward-Rainey 1997. Pleomorphic, non-motile, non-sporeforming rods. Atypical proteinaceous cell walls.

\section{Acknowledgements}

We thank I. Kramer for determining the full-length 16S rRNA gene sequence of $S$. thermophilus, $H$. Trüper for advice on the names of higher taxa and two anonymous reviewers for helpful comments on the manuscript.

\section{References}

Björnsson, L., Hugenholtz, P., Tyson, G. W. \& Blackall, L. L. (2002). Filamentous Chloroflexi (green non-sulfur bacteria) are abundant in wastewater treatment processes with biological nutrient removal. Microbiology 148, 2309-2318.

Carreto, L., Moore, E., Nobre, M. F., Wait, R., Riley, P. W., Sharp, R. J. \& da Costa, M. S. (1996). Rubrobacter xylanophilus sp. nov., a new thermophilic species isolated from a thermally polluted effluent. Int J Syst Bacteriol 46, 460-465.

Dalevi, D., Hugenholtz, P. \& Blackall, L. L. (2001). A multipleoutgroup approach to resolving division-level phylogenetic relationships using $16 \mathrm{~S}$ rDNA data. Int J Syst Evol Microbiol 51, 385-391.

Demharter, W., Hensel, R., Smida, J. \& Stackebrandt, E. (1989). Sphaerobacter thermophilus gen. nov., sp. nov., a deeply rooting member of the Actinomycetes subdivision isolated from thermophilically treated sewage sludge. Syst Appl Microbiol 11, 261-266.

Embley, T. M. \& Stackebrandt, E. (1994). The molecular phylogeny and systematics of the actinomycetes. Annu Rev Microbiol 48, 257-289.

Garrity, G. M. \& Holt, J. G. (2001a). Phylum BVI. Chloroflexi phy. nov. In Bergey's Manual of Systematic Bacteriology, 2nd edn, vol. 1, The Archaea and the Deeply Branching and Phototrophic Bacteria, p. 427. Edited by D. R. Boone, R. W. Castenholz \& G. M. Garrity. New York: Springer.

Garrity, G. M. \& Holt, J. G. (2001b). Phylum BVII. Thermomicrobia phy. nov. In Bergey's Manual of Systematic Bacteriology, 2nd edn, vol. 1, The Archaea and the Deeply Branching and Phototrophic Bacteria, p. 447. Edited by D. R. Boone, R. W. Castenholz \& G. M. Garrity. New York: Springer.
Hensel, R., Demharter, W. \& Hilpert, R. (1989). The microflora involved in aerobic-thermophilic sludge stabilization. Syst Appl Microbiol 11, 312-319.

Hugenholtz, P., Goebel, B. M. \& Pace, N. R. (1998). Impact of culture-independent studies on the emerging phylogenetic view of bacterial diversity. J Bacteriol 180, 4765-4774.

Janssen, P. H. \& Hugenholtz, P. (2003). Fermentation of glycolate by a pure culture of a strictly anaerobic Gram-positive bacterium belonging to the family Lachnospiraceae. Arch Microbiol 179, 321-328.

Maymó-Gatell, X., Chien, Y. T., Gossett, J. M. \& Zinder, S. H. (1997). Isolation of a bacterium that reductively dechlorinates tetrachloroethene to ethene. Science 276, 1568-1571.

Merkel, G. J., Durham, D. R. \& Perry, J. J. (1980). The atypical cell wall composition of Thermomicrobium roseum. Can J Microbiol 26, 556-559.

Monciardini, P., Cavaletti, L., Schumann, P., Rohde, M. \& Donadio, S. (2003). Conexibacter woesei gen. nov., sp. nov., a novel representative of a deep evolutionary line of descent within the class Actinobacteria. Int J Syst Evol Microbiol 53, 569-576.

Pond, J. L. \& Langworthy, T. A. (1987). Effect of growth temperature on the long-chain diols and fatty acids of Thermomicrobium roseum. J Bacteriol 169, 1328-1330.

Pond, J. L., Langworthy, T. A. \& Holzer, G. (1986). Long-chain diols: a new class of membrane lipids from a thermophilic bacterium. Science 231, 1134-1136.

Rainey, F. A. \& Stackebrandt, E. (1993). Phylogenetic evidence for the classification of Acidothermus cellulolyticus into the subphylum of Actinomycetes. FEMS Microbiol Lett 108, 27-30.

Rainey, F. A., Ward-Rainey, N., Kroppenstedt, R. M. \& Stackebrandt, E. (1996). The genus Nocardiopsis represents a phylogenetically coherent taxon and distinct actinomycete lineage: proposal for Nocardiopsaceae fam. nov. Int J Syst Bacteriol 46, 1088-1092.

Rappé, M. S., Gordon, D. A., Vergin, K. L. \& Giovannoni, S. J. (1999). Phylogeny of actinobacteria small subunit (SSU) rRNA gene clones recovered from marine bacterioplankton. Syst Appl Microbiol 22, 106-112.

Sekiguchi, Y., Yamada, T., Hanada, S., Ohashi, A., Harada, H. \& Kamagata, Y. (2003). Anaerolinea thermophila gen. nov., sp. nov. and Caldilinea aerophila gen. nov., sp. nov., novel filamentous thermophiles that represent a previously uncultured lineage of the domain Bacteria at the subphylum level. Int J Syst Evol Microbiol 53, 1843-1851.

Shooner, F. \& Tyagi, R. D. (1995). Microbial ecology of simultaneous thermophilic microbial leaching and digestion of sewage sludge. Can J Microbiol 41, 1071-1080.

Stackebrandt, E., Rainey, F. A. \& Ward-Rainey, N. L. (1997). Proposal for a new hierarchic classification system, Actinobacteria classis nov. Int J Syst Bacteriol 47, 479-491.

Wiegel, J. (1998). Anaerobic alkalithermophiles, a novel group of extremophiles. Extremophiles 2, 257-267.

Woese, C. R. (1987). Bacterial evolution. Microbiol Rev 51, 221-271. 